\title{
Article \\ Self-Leadership and Psychological Capital as Key Cognitive Resources for Shaping Health-Protective Behaviors during the COVID-19 Pandemic
}

\author{
Sherry A. Maykrantz ${ }^{1}{ }^{\oplus}$, Luke A. Langlinais ${ }^{2}{ }^{\oplus}$, Jeffery D. Houghton ${ }^{2}{ }^{\oplus}$ and Christopher P. Neck ${ }^{3, *}$ \\ 1 School of Health Sciences, Salisbury University, Salisbury, MD 21801, USA; samaykrantz@salisbury.edu \\ 2 Department of Management, West Virginia University, Morgantown, WV 26506, USA; \\ la10022@mix.wvu.edu (L.A.L.); jeff.houghton@mail.wvu.edu (J.D.H.) \\ 3 Department of Management and Entrepreneurship, Arizona State University, Tempe, AZ 85287, USA \\ * Correspondence: christopher.neck@asu.edu
}

Citation: Maykrantz, Sherry A.,

Luke A. Langlinais, Jeffery D.

Houghton, and Christopher P. Neck.

2021. Self-Leadership and

Psychological Capital as Key

Cognitive Resources for Shaping

Health-Protective Behaviors during

the COVID-19 Pandemic.

Administrative Sciences 11: 41

https://doi.org/10.3390/admsci11020041

Received: 1 March 2021

Accepted: 7 April 2021

Published: 12 April 2021

Publisher's Note: MDPI stays neutral with regard to jurisdictional claims in published maps and institutional affiliations.

\begin{abstract}
As COVID-19 has become a global pandemic, health researchers and practitioners have focused attention on identifying the factors that may help to shape health-protective behaviors, protecting individual health and well-being, and helping to mitigate the spread of COVID-19. This study explores the potential role of self-leadership and psychological capital (PsyCap) as key cognitive resources for shaping health-protective behaviors. Using multiple theoretical frameworks (social cognitive theory, psychological resources theory, and the health belief model), this paper develops and tests a hypothesized serial mediation model in which PsyCap and coping self-efficacy mediate the relationship between self-leadership and health-protective behaviors including hand washing, wearing face masks, and social distancing. Results suggest that PsyCap and coping selfefficacy mediate the positive relationship between self-leadership and health-protective behaviors. These results yield valuable insights regarding the usefulness of self-leadership and PsyCap as cognitive resources for shaping health-protective behaviors and for possible self-leadership and PsyCap interventions, potentially tailored to at-risk populations, which should have practical benefits for both the current and future pandemics and health crises.
\end{abstract}

Keywords: self-leadership; psychological capital (PsyCap); coping self-efficacy; health protective behaviors; COVID-19

\section{Introduction}

On 13 March 2020, the President of the United States declared a national emergencytravel restrictions were put into place, social distancing at all levels of society was suggested, and anyone who felt sick was advised to stay at home. By April 2020, the Centers for Disease Control and Prevention (CDC) recommended face coverings, hand washing, and social distancing to aid in slowing down the spread of the virus. While these preventive measures started as suggestions in the early stages of COVID-19, they quickly became mandatory around much of the world, resulting in hesitance and noncompliance. For instance, communicating about the effectiveness of mask wearing and social distancing has proven difficult due to a heighted sense of distrust in informational sources (Ali et al. 2020; Fridman et al. 2020). The CDC advocates the use of face coverings and highlights how they can drastically mitigate the spread of COVID-19 when worn properly (CDC 2021a). Likewise, the CDC recommends proper and frequent hand washing along with social distancing from others. Sadly, just one year following the initial CDC recommendations urging these health-protective behaviors, more than 500,000 deaths have resulted from COVID-19 in the United States alone (CDC 2021b). Undoubtedly, research investigating the potential barriers prohibiting people from practicing health-protective behaviors and the means for overcoming those barriers in the face of a global pandemic could have important implications for both the current and future health crises. 
One of the most effective and easily adopted actions people can take to reduce negative health outcomes is the practice of health-protective behaviors. In the current study, we define health-protective behaviors as the action of using a face covering, washing hands, and social distancing (at least 6 feet away). This concept of utilizing health-protective behaviors to prevent disease is not novel. For example, during the influenza pandemic of 1918 (i.e., Spanish Flu), face masks were used to help slow the spread of the virus (Little 2020) and while compliance was relatively high, the authorities of that time faced many of the same challenges in promoting this basic health-protective behavior as are faced today. As Little (2020) notes, "some complained that the masks were uncomfortable, ineffective or bad for business (para. 5)." Furthermore, the recommended use of facemasks in the period 1918-1919 created animosity towards political officials, resulting in political and cultural wars (Hauser 2020). Similar controversies and political battles have resulted during subsequent global pandemics (e.g., H2N2, H3N2, SARS, Swine Flu, MERS, and Ebola) and especially in the context of the current pandemic, demonstrating the need to better understand and shape the antecedents of health-protective behaviors.

Although health-protective factors have been gaining momentum for decades (e.g., Berkanovic 1981; Krick and Sobal 1990), much of the research to date has centered on medical treatments, which are often 'prescribed' by a doctor. Moreover, health-protective behaviors are often regarded as actions that help to maintain safety (i.e., wearing a seat belt, helmet). Prior to the current pandemic, few people would have anticipated that standing 6 feet apart or covering one's face would be among the most pivotal and important healthprotective behaviors of our time. Indeed, one of the key challenges in facilitating these behaviors in the current times has been individual attitudes toward these behaviors (e.g., it is my right not to wear a mask; it is not fashionable), while others have lacked confidence in their ability to wear a mask properly. In recent months, many states and municipalities have mandated facemasks and social distancing, resulting in slow shifts in the norms of compliance. Nevertheless, gaining a clear understanding of the factors that shape the attitudes and choices relating to these health-protective behaviors remains an important focus in public health research.

Certainly, health-protective behaviors extend far beyond simply taking medication or wearing a seat belt. Yet, very few studies to date have explored cognitive resources as a possible means for enhancing one's ability to voluntarily practice health-protective behaviors, specifically during a pandemic (for two notable exceptions see Ho et al. 2013; Prati et al. 2011). The current study takes a nuanced approach by marrying cognitive resources with health-protective behaviors. Specifically, our study explores the ways in which self-leadership and psychological capital (PsyCap) may serve as essential tools for positively shaping health-protective behaviors. Using multiple theoretical frameworks, we develop and test a hypothesized serial mediation model in which PsyCap and coping selfefficacy mediate the relationship between self-leadership and health-protective behaviors. Importantly, our model highlights how cognitive resources may be layered in sequential fashion, building upon one other to strengthen our ultimate outcome of interest, healthprotective behaviors.

\section{Literature Review}

\subsection{Self-Leadership}

Self-leadership is a comprehensive self-influence process involving both behavioral and cognitive strategies aimed at positively affecting behavior and performance outcomes (Manz 1986; Neck et al. 2020). Originally proposed as a specific substitute for traditional, vertical leadership (e.g., Manz and Sims 1980; Manz 1986), self-leadership has theoretical foundations in self-control theory (e.g., Thoresen and Mahoney 1974), self-regulation theory (e.g., Carver and Scheier 1998), and social cognitive theory (e.g., Bandura 1986). In particular, self-leadership processes operate within the context of social cognitive theory's triadic reciprocal model of behavior (Wood and Bandura 1989). This model suggests that human behavior is shaped by both internal factors, such as cognitive processes 
and other individual influences, and external environmental reinforcement contingencies (Wood and Bandura 1989).

Self-leadership's behavioral strategies, which include observing current behaviors as a baseline for improvement, setting specific and challenging behavioral goals, and creating self-set external reward contingencies, are aimed at managing external reinforcement factors to reshape and enhance behaviors in positive ways, especially those involving necessary but unpleasant tasks (Neck and Houghton 2006; Neck et al. 2020). Self-leadership's cognitive strategies, including focusing attention on natural rewards, positive self-talk, positive mental imagery, and reframing dysfunctional beliefs and assumptions, are designed to shape behaviors through internalized cognitive processes (Neck and Manz 1992, 1996; Neck and Houghton 2006). It is through the addition of these cognitive strategies that self-leadership provides a high level of self-influence than related self-influence concepts such as self-management (e.g., Andrasik and Heimberg 1982; Manz and Sims 1980) that focus only on behavioral self-regulation (Manz 1986).

Given its expanded focus on effectively shaping internalized cognitive processes, self-leadership is often portrayed as a key cognitive resource that can help to shape behavioral outcomes in positive ways (e.g., Neck et al. 2013). For instance, Godwin and his colleagues (Godwin et al.) proposed self-leadership as a key cognitive resource that could help protect entrepreneurs against the negative effects of environmental stressors and demands associated with being an entrepreneur, and would ultimately lead to enhanced entrepreneurial performance. Similarly, Neck and his colleagues (Neck et al. 2013) advanced a model in which self-leadership moderated the negative effects of hindrance and family stressors on exhaustion and ultimately exit and growth intentions for entrepreneurs. Finally, Lovelace et al. (2007) argued that self-leadership may serve as a cognitive resource capable of helping leaders reduce the psychological strain associated with job demands while increasing long-term perceptions of job control.

\subsection{Psychological Capital (PsyCap)}

Moving beyond self-leadership's constellation of behavioral and cognitive self-influence strategies and processes, psychological capital (PsyCap; Luthans et al. 2007) may serve as another, complementary cognitive resource for positively shaping behavioral outcomes. PsyCap may be described as a state-like, composite positive psychological resource that includes efficacy, which relates to beliefs about one's abilities to mobilize resources and take courses of action necessary to succeed, optimism, which involves making positive attributions about the likelihood one's chances of success, hope, which includes both goalfocused energy and goal-directed planning, and finally, resilience, which entails the ability to overcome and recover from adversity and failures (Luthans et al. 2007, p. 3).

PsyCap is conceptualized as a multi-dimensional construct with predictive validity exceeding its four dimensions alone, which in combination create "a synergistic effect, whereby the whole may be greater than the sum of its parts" (Dawkins et al. 2013, p. 350). Meta-analytics findings suggest that PsyCap is significantly positively related to a number of important employee attitudes, including job satisfaction, psychological well-being, and organizational commitment, and several employee performance outcomes (Avey et al. 2011). These findings also demonstrated a significant negative relationship between PsyCap and several detrimental employee attitudes and behaviors, including anxiety, stress, cynicism, turnover intentions, and workplace deviance (Avey et al. 2011). Notable among the empirical findings related to PsyCap, Avey and his colleagues (Avey et al. 2009) provided evidence supporting PsyCap as a key cognitive resource for reducing stress symptoms and intentions to quit in a sample of 416 working adults across a variety of industries and occupations.

\subsection{Coping Self-Efficacy}

The theory of stress and coping (Lazarus and Folkman 1984) describes stress as occurring when individuals perceive some aspect of their person-environment interface as 
both personally significant and exceeding their coping resources. Coping may be defined as individuals' behavioral or cognitive strivings to manage personal situations that they perceive as stressful (Lazarus and Folkman 1984). Coping approaches are often divided into two broad categories of adaptive and maladaptive coping (e.g., Holton et al. 2016). Maladaptive coping often occurs when people perceive stressors beyond their control and include detrimental health-related behaviors such as rumination, avoidance, overeating, and substance abuse (Holton et al. 2016). In contrast, people tend to engage in more adaptive coping strategies when they perceive the situation as controllable and these adaptive coping strategies can include health-protective behaviors such as exercise, meditation, and seeking social support (Holton et al. 2016).

Targeted cognitive-focused coping interventions, such as training specifically aimed at increasing coping effectiveness (e.g., Chesney et al. 2003), generally aim to increase adaptive coping skills, lower emotional suffering and improve subjective well-being. Meanwhile, self-efficacy, a central tenet of social cognitive theory, refers to an individuals' subjective self-assessment of their capabilities to successfully perform a specific task or activity (Bandura 1986). Coping self-efficacy, then, is defined as specific beliefs regarding one's capabilities to engage in key coping behaviors and strategies (Chesney et al. 2006). Individuals tend to appraise first whether a given situation is controllable through coping, and second, whether they believe they have the capabilities to carry out the necessary coping behaviors (Chesney et al. 2006). Consequently, coping self-efficacy should influence the effects of cognitive resource interventions on actual behavioral outcomes (Chesney et al. 2006). Indeed, many empirical studies have found evidence supporting the role of coping self-efficacy in mediating the effects of cognitive resources and related interventions on outcomes (e.g., Benight et al. 1999). For example, Cieslak et al. (2008) found that coping self-efficacy served as a mediating mechanism that reduced the effects of cognitive distortions on posttraumatic distress. Similarly, Sumer et al. (2005) reported that coping self-efficacy mediated the relationship between individuals' personal resources (including self-esteem, optimism, and perceived control) and psychological distress following an earthquake in Turkey. Finally, Luberto and her colleagues (Luberto et al. 2014) showed that coping self-efficacy mediated the relationship between mindfulness skills (including observing, describing, acting with awareness, and accepting without judgment) and emotion regulation difficulties.

\subsection{Health-Protective Behaviors}

As noted earlier, in the context of the current study, we define health-protective behaviors as wearing a facemask, hand washing, and social distancing; the actions one takes to prevent the spread of COVID-19. Historically, health-protective behaviors have been a staple for public health and have a long-standing place in disease prevention (Krick and Sobal 1990). Further, such behaviors serve a key function in the protection of people by reducing negative health outcomes, risk factors, and enabling healthy lifestyle (Rossman et al. 2017).

While only suggested at the beginning of the current pandemic, health-protective behaviors such as mask wearing rapidly became mandates in many public spaces, resulting in shifting attitudes and changing perceptions of norms and behavioral control. Despite these behavioral mandates, individual compliance with and attitudes toward forced health directives have varied greatly. For instance, Fridman et al. (2020) report that trust in informational sources affects adherence to socially distance in response to COVID-19, and results varied by gender and age. These findings underscore the extent to which healthprotective measures can be jeopardized based on lack of trust, perhaps stemming from past experiences. Qazi et al. (2020) reported similar findings in examining the role of informational sources, individual understanding of COVID-19, and the adoption of social distancing behaviors. Once again, trust played a role and was heavily linked to situational awareness (i.e., understanding). Lack of knowledge, perceptions of invulnerability, and asymptomatic spreading can all serve as key barriers for compliance. As noted above, researchers have afforded very little attention to cognitive resources as possible antecedents 
to health-protective behaviors. In developing and testing a model of the role of cognitive resources in shaping health-protective behaviors, the current study takes an important step toward filling this gap in our knowledge.

\section{Conceptual Model and Hypothesis Development}

In this section, using multiple theoretical frameworks, we develop and present a hypothesized serial mediation model of the relationships among self-leadership, PsyCap, coping self-efficacy, and health-protective behaviors. A diagram of our conceptual serial mediation model is shown in Figure 1.

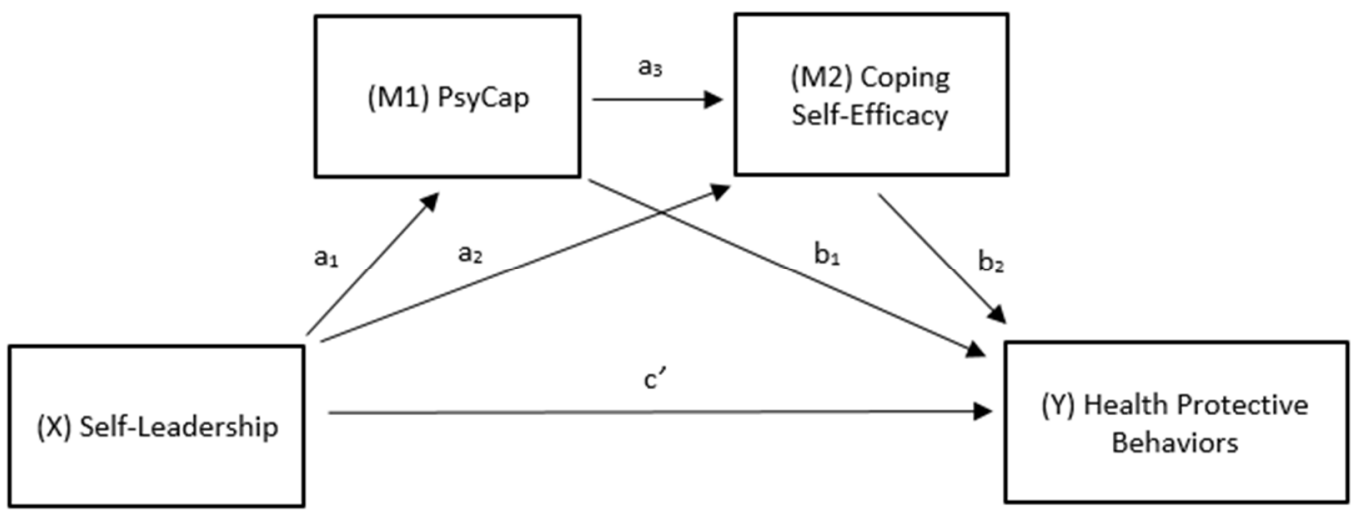

Figure 1. Conceptual Serial Mediation Model (Self-Leadership-Health-Protective Behaviors).

As noted above, social cognitive theory's triadic reciprocal model suggests multidirectional relationships between one's behavior, one's cognitive processes and other personal factors, and the external environment (Wood and Bandura 1989). Working within this theoretical context, we posit that self-leadership's cognitive-focused strategies and processes will help build an individual's cognitive resources in two ways. First, selfleading individuals should experience more constructive thought patterns, resulting in more positive and constructive self-talk, mental visualizations, and beliefs and assumptions (Neck et al. 2020). Second, engaging self-leading cognitive-focused strategies should enhance the cognitive resources associated with PsyCap, namely efficacy, optimism, hope, and resilience.

Empirical evidence supports this theory-based supposition (e.g., Kotzé 2018). For instance, Harunavamwe et al. (2020) reported that self-leadership strategies enhanced the psychological resources of PsyCap, which in turn were related to work engagement in a sample of 303 banking sector employees. Likewise, Kotzé (2021) reported that PsyCap mediated the relationship between personal resources (i.e., self-leadership and mindfulness) and psychological well-being (i.e., work engagement and burnout) in a sample of 226 public sector workers in South Africa. Finally and importantly, Gupta et al. (2020) showed that thought self-leadership (i.e., self-leadership's cognitive-focused strategies) is a significant antecedent to PsyCap. Consequently, it seems reasonable to suggest that self-leadership will be related to PsyCap and that PsyCap will also serve as a mediating mechanism in our conceptual model.

The social cognitive theory also supports the role of self-leadership in enhancing selfefficacy. Indeed, self-efficacy has been proposed as a primary outcome of self-leadership and a primary mediating mechanism through which self-leadership influences other outcomes (e.g., Neck and Houghton 2006), and a number of empirical studies have found a linkage between self-leadership and self-efficacy (e.g., Andressen et al. 2012; Ho and Nesbit 2009; Prussia et al. 1998). Moreover, self-leadership has been linked to coping and stress outcomes (e.g., Houghton et al. 2012b; Maykrantz and Houghton 2020; Wang et al. 2016). In particular, Slambl (2021) recently reported findings showing a strong relationship between self-leadership competencies and school leaders' perceived coping abilities in the midst of the COVID-19 pandemic in Jeddah, Saudi Arabia. Finally, as noted above, coping 
self-efficacy has been shown to mediate the relationship between cognitive resources and key outcomes (e.g., Luberto et al. 2014). Thus, based on this evidence, it seems logical to advance that coping self-efficacy will serve as a mediating mechanism for the effects of self-leadership and PsyCap on health-protective behaviors.

Psychological resources theory (Hobfoll 2002) provides additional support for our conceptual model. Psychological resources theory posits that psychological resources, especially resources arrayed in multidimensional constructs, have impressive potential for positively shaping health-related behaviors and well-being (e.g., Hobfoll 2002). As an example, Taylor et al. (2000) presented research results suggesting that psychological resources (including optimism, personal control, and a sense of meaning) affected health behaviors and outcomes. Self-leadership is a multidimensional construct with self-influence processes aimed at enhancing cognitive resources including optimism, feelings of self-control, and feelings of purpose and meaning (Neck et al. 2020). PsyCap is a multidimensional construct of psychological resources that may be enriched through self-leadership (e.g., Gupta et al. 2020). Hence, based on psychological resource theory, it appears to be reasonable to propose that self-leadership and PsyCap will both be related to health-protective behaviors and that PsyCap will mediate the relationship between self-leadership and health-protective behaviors.

The health belief model (Rosenstock et al. 1988) provides one additional theoretical underpinning for our conceptual model. This framework was originally developed to explain why people fail to engage in health screenings (Glanz et al. 2015) and has become one of the more widely used theories for explaining health behaviors (e.g., Carpenter 2010; Jones et al. 2015; Nobiling and Maykrantz 2017). The model includes six dimensions (i.e., perceived susceptibility, perceived severity, perceived barriers, perceived benefits, self-efficacy, and cues to action) that have shown effectiveness in predicting individual health behaviors (Carpenter 2010; Rosenstock et al. 1988). Relating this framework to our hypothesized conceptual model, self-leadership's cognitive-focused strategies have the potential to help people to overcome perceived barriers and visualize perceived benefits of health-protective behaviors (cf. Neck et al. 2020). In addition, self-leadership's behaviorfocused strategies (e.g., self-goal-setting and self-cueing) provide direct cues to action that may enhance health-protective behaviors. Finally and as mentioned above, both self-leadership and PsyCap are likely to facilitate coping self-efficacy, which should make people more likely to engage in health-protective behaviors in harmony with the health belief model. Taken together, the theoretical, logical, and empirical evidence outlined in this section provide strong support for our conceptual serial mediation model and serve as the basis for advancing the following hypothesis:

Hypothesis 1 (H1). Psychological capital (PsyCap) and coping self-efficacy mediate the positive relationship between self-leadership and health-protective behaviors.

\section{Method}

\subsection{Participants and Procedures}

Following approval from our university's Institutional Review Board, we recruited participants through the networks of undergraduate students in an introductory management course at a large mid-Atlantic university in the United States. To participate in this study, survey respondents were required to be a minimum of 18 years old. The data collection occurred during the first week of December 2020. We employed listwise deletion to remove cases that: (1) had missing data, (2) failed to meet the minimum inclusion criterion, and (3) failed to pass attention checks included in the survey. After cleaning the data in this manner, we arrived at a final sample size of 615. Participants had an average age of 31 and were $54 \%$ female, $84 \%$ White, $4 \%$ Black, $4 \%$ Hispanic, and 3\% Asian. The participants came from varied industries (11\% healthcare, $9 \%$ education, $7 \%$ retail). The participants reflected a number of political orientations including $41 \%$ Republican, $29 \%$ Democrat, 20\% Independent, 8\% None, and 2\% Other. There was a write-in field for "other" 
which included the following (numbers represent actual write ins, not percentages): 7 Libertarian, 1 Progressive, 1 Moderate, and 1 Bull Moose.

\subsection{Measures}

Self-leadership was measured using the 9-item Abbreviated Self-Leadership Questionnaire (ASLQ; Houghton et al. 2012a). Sample items are, "I establish specific goals for my own performance" and "I try to mentally evaluate the accuracy of my own beliefs about situations I am having problems with." Responses were solicited using a 5-point Likert-type scale ranging from "Not at all accurate" to "Completely accurate." The items showed acceptable reliability for the current data with a coefficient alpha of 0.79

PsyCap was measured using the 24-item Psychological Capital (PsyCap) Questionnaire (PCQ; Luthans et al. 2007). Sample items include, "I can get through difficult times at work because I've experienced difficulty before" and "There are a lot of ways around any problem." Responses were measured using a 6-point Likert-type scale ranging from "Strongly disagree" to "Strongly Agree." The items demonstrated solid reliability for our data with a coefficient alpha of 0.90 .

Coping self-efficacy was measured using the 26-item Coping Self-Efficacy Scale (Chesney et al. 2006). Items are introduced with the framing statement, "When things aren't going well for you, how confident are you that you can:" and sample items are, "Find solutions to your most difficult problems" and "Get emotional support from friends and family." Responses were recorded using a 10-point Likert-type scale ranging from "Cannot do at all" to "Certain can do." These items showed strong reliability for our data with a coefficient alpha of 0.94 .

Health-protective behaviors were measured using ten items developed for the present study. These items assessed both preventative actions (i.e., face masking and hand washing) and social distancing behaviors. Eight items measure preventative actions. Because face masking was mandated and hand washing strongly recommended in most parts of the United States at the time of our data collection, we created items designed to assess attitudes, perceived norms, and behavioral intentions related to face masking and hand washing rather than actual behaviors. However, the theory of planned behavior (e.g., Ajzen 2002) suggests that attitudes, norms, and behavioral intentions toward face masking serve as strong predictors of actual face masking and hand washing behaviors in the absence of the mandates and recommendations. Sample preventative action items include "Over the last several months, wearing a face mask/covering in public places has been: [7-point Likert-type scale ranging from bad to good]" and "I would continue to wear a face mask/covering in public places, even if it were no longer required [7-point Likert scale ranging from likely to unlikely]" and "I would continue to wash my hands frequently, even if it were no longer recommended [7-point Likert scale ranging from likely to unlikely]." Five items measured social distancing behaviors. Sample items include "In the past 30 days, I have avoided eating out due to COVID-19" and "In the past 30 days, I have avoided close interactions with friends and family due to COVID-19." Responses were collected using a 4-point Likert-type scale ranging from "Never" to "Always." The overall 13-item scale for health-protective behaviors showed good reliability for our data with a coefficient alpha of 0.84 .

\section{Results}

Descriptive statistics and correlations for all study variables are shown in Table 1. We tested the hypothesized model using Hayes' (2013) PROCESS Model 6 with 5000 bootstrapped samples and a 95\% confidence interval. Results of this analysis are summarized in Table 2. Self-leadership was regressed onto health-protective behaviors, with indirect effects operating through the two sequential mediators of PsyCap and coping self-efficacy. 
Table 1. Descriptive Statistics and Correlations.

\begin{tabular}{ccccccc}
\hline Variable & Mean & SD & $\mathbf{1}$ & $\mathbf{2}$ & $\mathbf{3}$ & $\mathbf{4}$ \\
\hline 1. Self-Leadership & 2.37 & 0.61 & $(0.79)$ & & & \\
2. Psychological Capital & 4.62 & 0.58 & $0.50^{*}$ & $(0.90)$ & & \\
3. Coping Self-Efficacy & 6.74 & 1.43 & $0.36^{*}$ & $0.62 *$ & $(0.94)$ & \\
4. Health-Protective Behaviors $^{*}$ & 0.00 & 0.59 & $0.18^{*}$ & $0.21^{*}$ & $0.21^{*}$ & $(0.84)$ \\
\hline
\end{tabular}

$N=615$. Composite reliability for each construct is on the diagonal in parentheses. ${ }^{a}$ HPB was centered with z-scores. ${ }^{*} p<0.01$.

Table 2. OLS Regression Coefficients and Indirect Effects.

\begin{tabular}{|c|c|c|c|c|c|c|}
\hline Regression Model & $B$ & SE & $t$ & $p$ & LLCI & ULCI \\
\hline \multicolumn{7}{|l|}{ Outcome: PsyCap } \\
\hline \multicolumn{7}{|l|}{$F(1,613)=206.02, p<0.001, R^{2}=0.25$} \\
\hline Constant & 2.805 & 0.128 & 21.873 & $<0.001$ & 2.553 & 3.057 \\
\hline Self-Leadership $\left(a_{1}\right)$ & 0.471 & 0.033 & 14.354 & $<0.001$ & 0.407 & 0.536 \\
\hline \multicolumn{7}{|l|}{ Outcome: Coping Self-Efficacy } \\
\hline \multicolumn{7}{|l|}{$F(2,612)=188.97, p<0.001, R^{2}=0.38$} \\
\hline Constant & -0.541 & 0.386 & -1.401 & 0.162 & -1.300 & 0.217 \\
\hline PsyCap $\left(a_{3}\right)$ & 1.435 & 0.091 & 15.751 & $<0.001$ & 1.256 & 1.614 \\
\hline Self-Leadership $\left(a_{2}\right)$ & 0.1676 & 0.086 & 1.958 & 0.051 & -0.001 & 0.336 \\
\hline \multicolumn{7}{|l|}{ Outcome: Health-Protective Behaviors } \\
\hline \multicolumn{7}{|l|}{$F(3,611)=12.96, p<0.001, R^{2}=0.06$} \\
\hline Constant & -1.11 & 0.196 & -5.631 & $<0.000$ & -1.491 & -0.720 \\
\hline PsyCap $\left(b_{1}\right)$ & 0.103 & 0.055 & 1.875 & 0.0612 & -0.005 & 0.211 \\
\hline Coping Self-Efficacy $\left(b_{2}\right)$ & 0.046 & 0.021 & 2.251 & $<0.05$ & 0.006 & 0.087 \\
\hline Self-Leadership $\left(c^{\prime}\right)$ & 0.083 & 0.044 & 1.895 & 0.059 & -0.003 & 0.168 \\
\hline & \multicolumn{6}{|c|}{ Bootstrapped } \\
\hline Indirect Effects and Serial Indirect Effect & SE & LLCI & ULCI & \multicolumn{3}{|c|}{$\mathrm{ab}_{\mathrm{cs}}$} \\
\hline $\mathrm{a}_{1} \mathrm{a}_{3} \mathrm{~b}_{2}\left(\mathrm{X} \rightarrow M_{1} \rightarrow M_{2} \rightarrow \mathrm{Y}\right)=0.032 *$ & 0.014 & 0.005 & 0.060 & \multicolumn{3}{|c|}{$0.033[0.005,0.062]$} \\
\hline $\mathrm{a}_{1} \mathrm{~b}_{1}\left(\mathrm{X} \rightarrow M_{1} \rightarrow \mathrm{Y}\right)=$ & 0.028 & -0.005 & 0.102 & \multicolumn{3}{|c|}{$0.051_{[-0.01,0.107]}$} \\
\hline $\mathrm{a}_{2} \mathrm{~b}_{2}\left(\mathrm{X} \rightarrow \mathrm{M}_{2} \rightarrow \mathrm{Y}\right)=$ & 0.006 & -0.001 & 0.021 & \multicolumn{3}{|c|}{$0.008[-0.001,0.02]$} \\
\hline
\end{tabular}

Note: Coefficients are unstandardized (B). Statistics generated using PROCESS in SPSS with 5000 bootstrapped samples and $95 \%$ bias-corrected confidence intervals (CIs). ${ }^{*}$ Lower- and upper-level confidence intervals (LLCI $\mathrm{ULCI}$ ) do not include zero and thus indicate significant mediation. $\mathrm{SE}=$ standard error; $\mathrm{M}_{1}=$ PsyCap; $\mathrm{M}_{2}=$ coping self-efficacy; $a_{\mathrm{cs}}=$ completely standardized indirect effect.

The total effect of the model was 0.170, with a total indirect effect of 0.088 [95\% CI: 0.044 , 0.134]. Our hypothesis was supported because the confidence interval was entirely above zero for the serial indirect effects $\left[a_{1} a_{3} b_{2}=0.032\right.$ (95\% CI: 0.005, 0.060); $\left.a_{1} a_{3} b_{2 c s}=0.033\right]$ with the effect of self-leadership on health-protective behaviors being transmitted serially $(X \rightarrow$ $\left.M_{1} \rightarrow M_{2} \rightarrow Y\right)$ through PsyCap $\left(M_{1}\right)$ and coping self-efficacy (M2). No other significant indirect effects were found independent of the serial mediation. The indirect effect $\left(X \rightarrow M_{1}\right.$ $\rightarrow Y$ ) for self-leadership on health-protective behaviors through PsyCap was not significant because the confidence interval contains zero $\left(a_{1} b_{1}=0.049\right.$ [95\% CI: $\left.\left.-0.005,0.102\right]\right)$. The indirect effect $\left(X \rightarrow M_{2} \rightarrow Y\right)$ through coping self-efficacy was likewise not significant $\left(a_{2} b_{2}=0.008\right.$ [ $95 \%$ CI: $\left.\left.-0.001,0.021\right]\right)$. Finally, the direct effects of $X$ (i.e., self-leadership) on Y (i.e., health-protective behaviors) in the model were also not significant $\left(c^{\prime}=0.083\right.$, $p=0.059$ ), thus underscoring the importance of the hypothesized serial mediation model for explaining the effects of self-leadership on health-protective behaviors.

\section{Discussion}

Our findings provide evidence in support of the idea that the effects of self-leadership on health-protective behaviors are transferred serially through the mediating mechanisms of PsyCap and coping self-efficacy, and that these indirect effects are significant even when controlling for the effects of other possible mediating paths. Our results showed that other indirect mediating paths were not statistically significant (e.g., $X \rightarrow M_{1} \rightarrow Y$ ), as were the direct paths from self-leadership to health-protective behaviors $\left(c^{\prime}\right)$ and from PsyCap 
to health-protective behaviors $\left(b_{1}\right)$. These findings thus suggest a key role for coping self-efficacy in transmitting the effects of psychological resources on health behaviors and outcomes. Still, our findings do not suggest full or complete mediation for the effects of self-leadership and PsyCap on health-protective behaviors. Complete mediation would require that all of the effects of $\mathrm{X}$ on $\mathrm{Y}$ are relayed via the mediation process and that both $b_{1}$ and $c^{\prime}=0$ (Hayes and Rockwood 2017). Our results suggest that some of the total effects of self-leadership and PsyCap on health-protective behaviors are transferred via direct linkages, even though these paths were not statistically significant for our sample data. In addition, other mediating variables not included in our hypothesized model could help to explain the relationships between self-leadership, PsyCap, and health-protective behaviors. Consequently, additional research is needed both to validate the findings reported here and to further develop the nomological network of the effects of cognitive resources on health behaviors. Our study has additional specific implications for research and practice that we discuss in greater detail below.

\subsection{Research Implications}

Our findings make at least three important contributions to self-leadership, PsyCap, and health behaviors research. First, our study helps to further establish self-leadership as a key potential antecedent for developing the cognitive resources (i.e., efficacy, optimism, hope, and resilience) of PsyCap (cf. Gupta et al. 2020; Harunavamwe et al. 2020; Kotzé 2018, 2021). Our results showed a strong direct relationship between self-leadership and PsyCap $\left(a_{1}=0.47, p<0.001\right)$. Second, our results help answer the call of Neck and Houghton (2006) to more clearly delineate the mediating mechanisms through which self-leadership effects valued outcomes. The model explored here suggests that self-leadership strategies and processes are translated into the positive cognitive resources of PsyCap, which in turn enhance coping self-efficacy and ultimately health behaviors. These findings support and expand on the established role of self-efficacy as a primary mediating mechanism for the effects of self-leadership on valued outcomes (cf. Andressen et al. 2012; Ho and Nesbit 2009; Prussia et al. 1998). Third, our findings help to further establish both self-leadership and PsyCap as principal cognitive resources for shaping health-related outcomes and behaviors. Although both self-leadership and PsyCap have been advanced as possible means for facilitating health-related outcomes (e.g., Neck et al. 2020; Schelleman-Offermans and Massar 2020), empirical support has been relative scant to date. The results reported here may help to serve as a springboard for additional research exploring self-leadership, PsyCap, and health-related outcomes.

\subsection{Practical Implications}

The findings from this study also offer several important practical implications. First, our results suggest that cognitive resources, such as self-leadership and PsyCap, do in fact relate to more positive health-protective behaviors. This suggests that helping people to enhance and build their reserves of cognitive resources may have important applications beyond the traditional scope of mental health outcomes alone (cf. Taylor et al. 2000).

Second, our results further reveal that the positive effects of individual cognitive resources may be largely transmitted via coping self-efficacy. Building on recent findings advancing self-leadership as effective tool for enhancing coping among college students (Maykrantz and Houghton 2020), the current study unveils how one's belief in one's capabilities to cope effectively may be enriched through the joint influences of self-leadership and PsyCap, resulting in healthier coping and ultimately more positive health-protective attitudes and behaviors.

Third, as Chesney et al. (2006) explain, "beliefs about one's ability to perform specific coping behaviours ... would be expected to influence outcomes of interventions designed to improve coping" (p. 422). Public health is grounded in the protection of people, and specifically the prevention of illness and disease, through various types of health interventions and messaging. Importantly, both self-leadership and PsyCap are amenable to 
enhancement through training interventions (e.g., Luthans et al. 2008; Stewart et al. 1996), which provides justification for the potential of a variety pathways (i.e., schools, organizations, churches, communities) for building psychological capital in the general population. These training interventions may draw upon multiple cognitive resources to help shape health-protective behaviors, creating tailored training interventions aimed at specific at-risk target populations for maximum benefits. Organizational leaders, in particular, would be well advised to consider self-leadership and PsyCap interventions that may help employees to protect themselves while keeping the organization and its customers safe and in compliance with regulations and mandates, thus preventing costly shutdowns and negative public relations.

Finally, health-protective behaviors could also be shaped by public health messaging aimed at activating the cognitive resources and processes of self-leadership and PsyCap. In particular, gain-framed messages (e.g., Rothman and Salovey 1997) delivered through mass media campaigns, social media, and/or personalized text messaging may be effective at facilitating the processes described in our model. As O'Keefe and Jensen (2007) explain, "in disease prevention messages, a gain-framed persuasive appeal emphasizes the advantages of compliance with the communicator's recommendation or viewpoint, as contrasted with loss-framed appeals, which emphasize the disadvantages of noncompliance." These researchers used meta-analytic techniques to show the relative effectiveness of gain-framed messaging over loss-framed messaging ( $\mathrm{O}^{\prime}$ Keefe and Jensen 2007, 2008). Applied to the context of our model and the COVID-19 pandemic, gain-framed messages extolling the advantages of heath protective behaviors such as masking, hand washing, and social distancing could trigger the activation of cognitive resources and processes such as self-goal setting (e.g., I will maintain appropriate distance from others when in public), self-reward (e.g., I will congratulate myself for wearing my mask to keep myself and others healthy and safe), optimism (e.g., I am making a difference in helping to stop the spread of the virus), resilience (e.g., I will continue to engage in health-protective behaviors even if I am experiencing fatigue and frustration), and ultimately coping self-efficacy (e.g., I feel I am capable of coping with the challenges of the pandemic). Empirical research (e.g., Bassett-Gunter et al. 2014) suggests that gain-framed health-focused messages activate various types of cognitive resources and processes. Future research should explore the extent to which messaging can activate self-leadership and PsyCap resources and processes in the context of health promotion. However, we do not mean to suggest that engaging cognitive resources resulting in coping self-efficacy and health-protective behaviors as described in our model would entirely stop the current or future pandemics. Rather, an understanding of these processes may aid in the preparation for and mitigation of the negative effects of future pandemics and health crises.

\subsection{Limitations and Future Research}

Despite the implications for research and practice outlined above, our study is subject to certain important limitations. First, this study employed a network sampling technique through which undergraduate students recruited the study participants. Network sampling has the potential to result in a sample that is non-representative of the overall population because students tend to recruit friends and family members from their social networks. This tends to narrow the range of possible participants to specific subpopulations, such as upper-middle-class families. Although there appears to be no reason to speculate that our findings would be different across various subpopulations, our findings should nevertheless be interpreted with a degree of caution. Second, our methodology involved the use of a cross-sectional design with self-reported data. Consequently, causal attributions cannot be made based on our data. For example, one might argue that the cognitive resources of self-leadership and PsyCap might just as easily be used to enhance negative noncompliant health behaviors (e.g., resolving not to wear a mask in public unless forced to do so). Although in developing our hypothesized conceptual model we advanced theoretical and logical arguments in support of causal effects, especially the key role of coping self-efficacy 
in triggering the positive health-protective behaviors explored here, it is the task of future research to more fully explore these relationships using longitudinal or experimental research designs. Third, cross-sectional data are particularly vulnerable to the threat of common method variance (e.g., Lindell and Whitney 2001). While research methods experts debate the extent to which common method variance is a problem, with some suggesting its deleterious effects are overstated or misunderstood (Malhotra et al. 2006; Spector 2006; Spector et al. 2019), our study design incorporated some specific ex ante strategies aimed at reducing the possibility of common method biases including using different scale endpoints and formats for the measurement of each construct and using attention check items (Podsakoff et al. 2003). Here, again, the reader is warned to apply caution in interpreting our findings.

Future research should explore the role of additional cognitive resources and processes, such as mindfulness (e.g., Bishop et al. 2004) and grit (e.g., Duckworth and Quinn 2009), in shaping health behaviors and outcomes. Researchers should also continue to probe the roles of both self-leadership and PsyCap as cognitive resources for shaping various types of health-protective behaviors beyond those explored here. For example, self-leadership and/or PsyCap could serve as important resources to help buffer against a relapse into substance abuse. Future research should also continue to explore the role of coping selfefficacy as a mediating mechanism for transferring the effects of various cognitive resources and interventions to various health behavior outcomes. For instance, as noted above, both self-leadership and PsyCap are amenable to change, and training intervention research studies have been conducted for both (e.g., Luthans et al. 2008; Stewart et al. 1996). A future longitudinal training effects study could delve more deeply into the causal effects of self-leadership, PsyCap, and coping self-efficacy on health-protective behaviors. Finally, although less academically explored, seriously looking at conspiracy theories, partisanship, and lack of trust on out-group collectives as explanatory variables may be illuminating.

\subsection{Conclusions}

In summary, our study offers insights into the roles of both self-leadership and PsyCap as important cognitive resources for shaping coping self-efficacy and ultimately healthprotective attitudes and behaviors. Our findings suggest that future research should be advanced to further clarify the value of cognitive resources in shaping health-related outcomes and behaviors and that interventions aimed at enhancing cognitive resources such as self-leadership and PsyCap in workplaces and communities should be seriously considered. The practical benefits of these endeavors could have far-reaching impacts, for both current and future pandemics and health crises.

Author Contributions: Conceptualization, S.A.M., L.A.L., J.D.H. and C.P.N.; methodology, S.A.M., J.D.H., L.A.L.; software, L.A.L.; formal analysis, L.A.L.; investigation, S.A.M., L.A.L., and J.D.H.; data curation, L.A.L.; writing — original draft preparation, S.A.M. and J.D.H.; writing-review and editing, C.P.N.; visualization, L.A.L. and J.D.H.; supervision, C.P.N.; project administration, S.A.M. and J.D.H. All authors have read and agreed to the published version of the manuscript.

Funding: This research received no external funding.

Institutional Review Board Statement: The study was approved by the Institutional Review Board of West Virginia University (protocol number 2011159116; approval date 4 November 2020).

Informed Consent Statement: Informed consent was obtained from all subjects involved in the study.

Data Availability Statement: Data available on request due to privacy restrictions. The data presented in this study are available on request from the corresponding author. The data are not publicly available due to authors preference.

Conflicts of Interest: All authors declare that they have no conflict of interest. 


\section{References}

Ajzen, Icek A. 2002. Perceived behavioral control, self-efficacy, locus of control, and the theory of planned behavior. Journal of Applied Social Psychology 32: 665-83. [CrossRef]

Ali, Shahmir H., Joshua Foreman, Yesim Tozan, Ariadna Capasso, Abbey M. Jones, and Ralph J. DiClemente. 2020. Trends and Predictors of COVID-19 Information Sources and Their Relationship with Knowledge and Beliefs Related to the Pandemic: Nationwide Cross-Sectional Study. JMIR Public Health and Surveillance 6: e21071. [CrossRef] [PubMed]

Andrasik, Frank, and Judy S. Heimberg. 1982. Self-Management Procedures. In Handbook of Organizational Behavior Management. Edited by Lee W. Frederikson. New York: Wiley, pp. 219-47.

Andressen, Panja, Udo Konradt, and Christopher P. Neck. 2012. The relation between self-leadership and transformational leadership: Competing models and the moderating role of virtuality. Journal of Leadership E Organizational Studies 19: 68-82.

Avey, James B., Fred Luthans, and Susan M. Jensen. 2009. Psychological capital: A positive resource for combating employee stress and turnover. Human Resource Management 48: 677-93. [CrossRef]

Avey, James B., Rebecca J. Reichard, Fred Luthans, and Ketan H. Mhatre. 2011. Meta-analysis of the impact of positive psychological capital on employee attitudes, behaviors, and performance. Human Resource Development Quarterly 22: 127-52. [CrossRef]

Bandura, Albert. 1986. Social Foundations of Thought and Action: A Social Cognitive Theory. Englewood Cliffs: Prentice-Hall.

Bassett-Gunter, Rebecca L., Amy E. Latimer-Cheung, Kathleen A. Martin Ginis, and Monica Castelhano. 2014. I spy with my little eye: Cognitive processing of framed physical activity messages. Journal of Health Communication 19: 676-91. [CrossRef] [PubMed]

Benight, Charles C., Erika Swift, Jean Sanger, Anne Smith, and Dan Zeppelin. 1999. Coping self-efficacy as a mediator of distress following a natural disaster. Journal of Applied Social Psychology 29: 2443-64. [CrossRef]

Berkanovic, Emil. 1981. Who Engages in Health Protective Behaviors? International Quarterly of Community Health Education 2: 225-37. [CrossRef]

Bishop, Scott R., Mark Lau, Shauna Shapiro, Linda Carlson, Nicole D. Anderson, James Carmody, Zindel V. Segal, Susan Abbey, Michael Speca, Drew Velting, and et al. 2004. Mindfulness: A proposed operational definition. Clinical Psychology: Science and Practice 11: 230-41. [CrossRef]

Carpenter, Christopher J. 2010. A meta-analysis of the effectiveness of Health Belief Model variables in predicting behavior. Health Communication 25: 661-69. [CrossRef]

Carver, Charles S., and Michael F. Scheier. 1998. On the Self-Regulation of Behavior. Cambridge: Cambridge University Press.

Centers for Disease Control and Prevention. 2021a. COVID-19: Considerations for Wearing Masks; Washington, DC: Centers for Disease Control and Prevention. Available online: https:/ /www.cdc.gov/coronavirus/2019-ncov/prevent-getting-sick/cloth-face-coverguidance.html (accessed on 21 February 2021).

Centers for Disease Control and Prevention. 2021b. CDC COVID Data Tracker; Washington, DC: Centers for Disease Control and Prevention. Available online: https:/ / covid.cdc.gov/covid-data-tracker/\#cases_casesper100klast7days (accessed on 21 February 2021).

Chesney, Margaret A., Donald B. Chambers, Jonelle M. Taylor, Lisa M. Johnson, and Susan Folkman. 2003. Coping effectiveness training for men living with HIV: Results from a randomized clinical trial testing a group-based intervention. Psychosomatic Medicine 65: 1038-46. [CrossRef]

Chesney, Margaret A., Torsten B. Neilands, Donald B. Chambers, Jonelle M. Taylor, and Susan Folkman. 2006. A validity and reliability study of the coping self-efficacy scale. British Journal of Health Psychology 11: 421-37. [CrossRef]

Cieslak, Roman, Charles C. Benight, and Victoria Caden Lehman. 2008. Coping self-efficacy mediates the effects of negative cognitions on posttraumatic distress. Behaviour Research and Therapy 46: 788-98. [CrossRef]

Dawkins, Sarah, Angela Martin, Jenn Scott, and Kristy Sanderson. 2013. Building on the positives: A psychometric review and critical analysis of the construct of psychological capital. Journal of Occupational \& Organizational Psychology 86: 348-70.

Duckworth, Angela Lee, and Patrick D. Quinn. 2009. Development and validation of the Short Grit Scale (GRIT-S). Journal of Personality Assessment 91: 166-74. [CrossRef]

Fridman, Ilona, Nicole Lucas, Debra Henke, and Christina K. Zigler. 2020. Association Between Public Knowledge About COVID-19, Trust in Information Sources, and Adherence to Social Distancing: Cross-Sectional Survey. JMIR Public Health and Surveillance 6: e22060. [CrossRef] [PubMed]

Glanz, Karen, Barbara K. Rimer, and K. Viswanath. 2015. Health Behavior: Theory, Research, and Practice, 5th ed. San Francisco: Jossey-Bass.

Godwin, Jeffrey L., Christopher P. Neck, and Robert S. D'Intino 2016. Self-leadership, spirituality, and entrepreneur performance: A conceptual model. Journal of Management, Spirituality E Religion 13: 64-78.

Gupta, Bindu, Rakesh Singh, Sandeep Puri, and Pankaj Rawat. 2020. Psychological Capital and Performance: Roles of Thought Self-Leadership, Engagement, and Feedback. In Academy of Management Proceedings. Briarcliff Manor: Academy of Management, p. 19263.

Harunavamwe, Martha, Petrus Nel, and Ebben Van Zyl. 2020. The influence of self-leadership strategies, psychological resources, and job embeddedness on work engagement in the banking industry. South African Journal of Psychology 50: 507-19. [CrossRef]

Hauser, Christine. 2020. The mask slackers of 1918. The New York Times. August 3. Available online: https://www.nytimes.com/2020 /08/03/us/mask-protests-1918.html (accessed on 25 February 2021). 
Hayes, Andrew F. 2013. Introduction to Mediation, Moderation, and Conditional Process Analysis: A Regression-Based Approach. New York: Guilford.

Hayes, Andrew F., and Nicholas J. Rockwood. 2017. Regression-based statistical mediation and moderation analysis in clinical research: Observations, recommendations, and implementation. Behaviour Research and Therapy 98: 39-57. [CrossRef]

Hobfoll, Stevan E. 2002. Social and psychological resources and adaptation. Review of General Psychology 6: 307-24. [CrossRef]

Ho, Jessie, and Paul L. Nesbit. 2009. A refinement and extension of the self-leadership scale for the Chinese context. Journal of Managerial Psychology 24: 450-76. [CrossRef]

Ho, Shirley S., Xianghong Peh, and Veronica W. L. Soh. 2013. The cognitive mediation model: Factors influencing public knowledge of the H1N1 pandemic and intention to take precautionary behaviors. Journal of Health Communication 18: 773-94. [CrossRef]

Holton, Kim, Adam E. Barry, and J. Don Chaney. 2016. Employee stress management: An examination of adaptive and maladaptive coping strategies on employee health. Work 53: 299-305. [CrossRef] [PubMed]

Houghton, Jeffery D., David Dawley, and Trudy C. DiLiello. 2012a. The abbreviated self-leadership questionnaire (ASLQ): A more concise measure of self-leadership. International Journal of Leadership Studies 7: 216-32.

Houghton, Jeffery D., Jinpei Wu, Jeffrey L. Godwin, Christopher P. Neck, and Charles C. Manz. 2012b. Effective stress management: A model of emotional intelligence, self-leadership, and student stress coping. Journal of Management Education 36: 220-38. [CrossRef]

Jones, Christina L., Jacob D. Jensen, Courtney L. Scherr, Natasha R. Brown, Katheryn Christy, and Jeremy Weaver. 2015. The health belief model as an explanatory framework in communication research: Exploring parallel, serial, and moderated mediation. Health Communication 30: 566-76. [CrossRef] [PubMed]

Kotzé, Martina. 2018. The influence of psychological capital, self-leadership, and mindfulness on work engagement. South African Journal of Psychology 48: 279-92. [CrossRef]

Kotzé, Martina. 2021. The relationship between public service employees' personal resources and psychological well-being. International Review of Administrative Sciences. [CrossRef]

Krick, John P., and Jeffery Sobal. 1990. Relationships between health protective behaviors. Journal of Community Health 15: 19-34. [CrossRef]

Lazarus, Richard S., and Susan Folkman. 1984. Stress, Appraisal, and Coping. New York: Springer.

Lindell, Michael K., and David J. Whitney. 2001. Accounting for common method variance in cross-sectional research designs. Journal of Applied Psychology 86: 114. [CrossRef]

Little, Becky. 2020. When Mask-Wearing Rules in the 1918 Pandemic Faced Resistance. Available online: https:/ / www.history.com/ news/1918-spanish-flu-mask-wearing-resistance (accessed on 28 February 2021).

Lovelace, Kathi J., Charles C. Manz, and Jose C. Alves. 2007. Work stress and leadership development: The role of self-leadership, shared leadership, physical fitness and flow in managing demands and increasing job control. Human Resource Management Review 17: 374-87. [CrossRef]

Luberto, Christina M., Sian Cotton, Allison C. McLeish, Carolyn J. Mingione, and Emily M. O’Bryan. 2014. Mindfulness skills and emotion regulation: The mediating role of coping self-efficacy. Mindfulness 5: 373-80. [CrossRef]

Luthans, Fred, Bruce J. Avolio, James B. Avey, and Steven M. Norman. 2007. Positive psychological capital: Measurement and relationship with performance and satisfaction. Personnel Psychology 60: 541-72. [CrossRef]

Luthans, Fred, James B. Avey, and Jaime L. Patera. 2008. Experimental analysis of a web-based training intervention to develop positive psychological capital. Academy of Management Learning E Education 7: 209-21.

Malhotra, Naresh K., Sung S. Kim, and Ashutosh Patil. 2006. Common method variance in IS research: A comparison of alternative approaches and a reanalysis of past research. Management Science 52: 1865-83. [CrossRef]

Manz, Charles C. 1986. Self-leadership: Toward an expanded theory of self-influence processes in organizations. Academy of Management Review 11: 585-600. [CrossRef]

Manz, Charles C., and Henry P. Sims Jr. 1980. Self-management as a substitute for leadership: A social learning perspective. Academy of Management Review 5: 361-67. [CrossRef]

Maykrantz, Sherry A., and Jeffery D. Houghton. 2020. Self-leadership and stress among college students: Examining the moderating role of coping skills. Journal of American College Health 68: 89-96. [CrossRef]

Neck, Christopher P., and Charles C. Manz. 1992. Thought Self-Leadership: The Influence of Self-Talk and Mental Imagery on Performance. Journal of Organizational Behavior 13: 681-99. [CrossRef]

Neck, Christopher P., and Charles C. Manz. 1996. Thought Self-Leadership: The Impact of Mental Strategies Training on Employee Cognition, Behavior, and Affect. Journal of Organizational Behavior 17: 445-67. [CrossRef]

Neck, Christopher P., and Jeffery D. Houghton. 2006. Two decades of self-leadership theory and research: Past developments, present trends, and future possibilities. Journal of Managerial Psychology 21: 270-95. [CrossRef]

Neck, Christopher P., Charles C. Manz, and Jeffery D. Houghton. 2020. Self-Leadership: The Definitive Guide to Personal Excellence (2e). Thousand Oaks: SAGE Publications.

Neck, Christopher P., Jeffery D. Houghton, Shruti R. Sardeshmukh, Michael Goldsby, and Jeffery L. Godwin. 2013. Self-leadership: A cognitive resource for entrepreneurs. Journal of Small Business E Entrepreneurship 26: 463-80.

Nobiling, Brandye D., and Sherry A. Maykrantz. 2017. Exploring perceptions about and behaviors related to mental illness and mental health service utilization among college students using the Health Belief Model (HBM). American Journal of Health Education 48 : 306-19. [CrossRef] 
O'Keefe, Daniel J., and Jakob D. Jensen. 2007. The relative persuasiveness of gain-framed loss-framed messages for encouraging disease prevention behaviors: A meta-analytic review. Journal of Health Communication 12: 623-44.

O'Keefe, Daniel J., and Jakob D. Jensen. 2008. Do loss-framed persuasive messages engender greater message processing than do gain-framed messages? A meta-analytic review. Communication Studies 59: 51-67. [CrossRef]

Podsakoff, Philip M., Scott B. MacKenzie, Jeong-Yeon Lee, and Nathan P. Podsakoff. 2003. Common method biases in behavioral research: A critical review of the literature and recommended remedies. Journal of Applied Psychology 88: 879-903. [CrossRef]

Prati, Gabriele, Luca Pietrantoni, and Bruna Zani. 2011. A social-cognitive model of pandemic influenza H1N1 risk perception and recommended behaviors in Italy. Risk Analysis: An International Journal 31: 645-56. [CrossRef]

Prussia, Gregory E., Joe S. Anderson, and Charles C. Manz. 1998. Self-leadership and performance outcomes: The mediating influence of self-efficacy. Journal of Organizational Behavior 19: 523-38. [CrossRef]

Qazi, Atika, Javaria Qazi, Khulla Naseer, Muhammad Zeeshan, Glenn Hardaker, Jaafar Z. Maitama, and Khalid Haruna. 2020. Analyzing situational awareness through public opinion to predict adoption of social distancing amid pandemic COVID-19. Journal of Medical Virology 92: 849-55. [CrossRef] [PubMed]

Rosenstock, Irwin M., Victor J. Strecher, and Marshall H. Becker. 1988. Social learning theory and the Health Belief Model. Health Education Quarterly 15: 175-83. [CrossRef] [PubMed]

Rossman, Christian, Michaela O'Brian, Gloria Poisson, and Abubakry Tunkra. 2017. Models and mechanisms of public health. In Chapter 5: Key Principles of Health Behavior Change. Available online: https://courses.lumenlearning.com/suny-buffaloenvironmentalhealth/part/chapter-5/ (accessed on 25 February 2021).

Rothman, Alexander J., and Peter Salovey. 1997. Shaping perceptions to motivate healthy behavior: The role of message framing. Psychological Bulletin 121: 3. [CrossRef]

Schelleman-Offermans, Karen, and Karlijn Massar. 2020. Explaining socioeconomic inequalities in self-reported health outcomes: The mediating role of perceived life stress, financial self-reliance, psychological capital, and time perspective orientations. PLoS ONE 15: e0243730. [CrossRef]

Slambl, James. K. 2021. The effect of self-leadership competencies on the perceived ability of school leaders to cope with COVID-19 pandemic crisis challenges in Jeddah schools, Saudi Arabia. Research \& Reviews: Journal of Educational Studies 7: 1-13.

Spector, Paul E. 2006. Method variance in organizational research: Truth or urban legend? Organizational Research Methods 9: 221-32.

Spector, Paul E., Christopher C. Rosen, Hettie A. Richardson, Larry J. Williams, and Russell E. Johnson. 2019. A new perspective on method variance: A measure-centric approach. Journal of Management 45: 855-80. [CrossRef]

Stewart, Greg L., Kenneth P. Carson, and Robert L. Cardy. 1996. The joint effects of conscientiousness and self-leadership training on employee self-directed behavior in a service setting. Personnel Psychology 49: 143-64. [CrossRef]

Sumer, Nebi, Nuray A. Karanci, Sibel K. Berument, and Hatice Gunes. 2005. Personal resources, coping self-efficacy, and quake exposure as predictors of psychological distress following the 1999 earthquake in Turkey. Journal of Traumatic Stress: Official Publication of The International Society for Traumatic Stress Studies 18: 331-42. [CrossRef]

Taylor, Shelley E., Margaret E. Kemeny, Geoffrey M. Reed, Julienne E. Bower, and Tara L. Gruenewald. 2000. Psychological resources, positive illusions, and health. American Psychologist 55: 99. [CrossRef]

Thoresen, Carl E., and Michael J. Mahoney. 1974. Behavioral Self-Control. New York: Holt Rinehart \& Winston.

Wang, Yefei, Guangrong Xie, and Xilong Cui. 2016. Effects of emotional intelligence and selfleadership on students' coping with stress. Social Behavior and Personality: An International Journal 44: 853-64. [CrossRef]

Wood, Robert, and Albert Bandura. 1989. Social cognitive theory of organizational management. Academy of Management Review 14: 361-84. [CrossRef] 